\title{
Screening and Follow-Up Monitoring for Substance Use in Primary Care: An Exploration of Rural-Urban Variations
}

\author{
Ya-Fen Chan, $P h D^{7}$, Shou-En Lu, PhD' ${ }^{2}$, Bill Howe, $P h D^{3}$, Hendrik Tieben, D.Sc. ${ }^{4}$, Theresa Hoeft, PhD', \\ and Jürgen Unützer, $M D, M A, M P H^{\top}$
}

'Department of Psychiatry \& Behavioral Sciences, School of Medicine, University of Washington, Seattle, WA, USA; ${ }^{2}$ Department of Biostatistics, School of Public Health, Rutgers University, Newark, NJ, USA; ${ }^{3}$ Department of Computer Science \& Engineering, University of Washington, Seattle, WA, USA; ${ }^{4}$ School of Architecture, Chinese University of Hong Kong, Shatin, NT, Hong Kong.

BACKGROUND: Rates of substance use in rural areas are close to those of urban areas. While recent efforts have emphasized integrated care as a promising model for addressing workforce shortages in providing behavioral health services to those living in medically underserved regions, little is known on how substance use problems are addressed in rural primary care settings.

OBJECTIVE: To examine rural-urban variations in screening and monitoring primary care- based patients for substance use problems in a state-wide mental health integration program.

DESIGN: This was an observational study using patient registry.

SUBJECTS: The study included adult enrollees ( $n=15,843)$ with a mental disorder from 133 participating community health clinics.

MAIN OUTCOMES: We measured whether a standardized substance use instrument was used to screen patients at treatment entry and to monitor symptoms at follow-up visits.

KEY RESULTS: While on average $73.6 \%$ of patients were screened for substance use, follow-up on substance use problems after initial screening was low (41.4\%); clinics in small/isolated rural settings appeared to be the lowest (13.6\%). Patients who were treated for a mental disorder or substance abuse in the past and who showed greater psychiatric complexities were more likely to receive a screening, whereas patients of small, isolated rural clinics and those traveling longer distances to the care facility were least likely to receive follow-up monitoring for their substance use problems.

CONCLUSIONS: Despite the prevalent substance misuse among patients with mental disorders, opportunities to screen this high-risk population for substance use and provide a timely follow-up for those identified as at risk remained overlooked in both rural and urban areas. Rural residents continue to bear a disproportionate burden of substance use problems, with rural-urban disparities found to be most salient in providing the continuum of services for patients with substance use problems in primary care.

Received March 6, 2015

Revised June 16, 2015

Accepted July 23, 2015

Published online August 13, 2015
KEY WORDS: substance screening and monitoring; rural-urban; primary health care.

J Gen Intern Med 31(2):215-22

DOI: $10.1007 / \mathrm{s} 11606-015-3488-y$

(C) Society of General Internal Medicine 2015

\section{INTRODUCTION}

Recent national statistics have shown that rates of substance use in rural areas are close to those in urban areas. ${ }^{1}$ Of particular concern is the high rate of binge drinking and misuse of prescription drugs among young rural residents. ${ }^{2,3}$ Yet, availability of substance abuse treatment in rural areas is scarce, and almost half of treatment admissions are referred by the criminal justice system. ${ }^{4}$ Individuals with substance use disorders often suffer from multiple comorbid psychiatric conditions, physical illness and social problems; however, only a small proportion seek or receive adequate treatment. ${ }^{5-}$ ${ }^{8}$ Failure to identify and provide timely monitoring and intervention to individuals at risk for substance use disorders results in missed opportunities for those who may benefit from treatment.

Rural residents experience greater disparities in access to health care than urban dwellers, in particular for preventive health services and specialty psychiatric treatment. ${ }^{9-12}$ Prior research on federally qualified health centers further showed that depression disease management yielded greater clinical benefits in urban than in rural patients. ${ }^{13}$ Overall, underdiagnosed and under-treated substance use and mental disorders remain salient among disadvantaged, underserved populations who are racial/ethnic minorities, low-income, lack health insurance, and/or reside in rural areas. ${ }^{14-16}$ Addressing these unmet-service needs, narrowing rural-urban health disparities, and improving coordination of care between different treatment sectors are pressing policy challenges. Integrating substance abuse and mental health services into primary care is a promising approach to address service needs that emphasizes problem identification, monitoring, brief interventions, and specialty referral when needed. The need for such integration can be witnessed through the growing demands for substance abuse and mental health services at safety-net community health clinics. ${ }^{17,18}$ 
While numerous studies have focused on access to mental health services in primary care, little information is available on how substance use problems are managed in rural community health clinics. Using data from a state-wide integrated care program, this study examines rural-urban variations in screening patients for substance use at treatment entry and monitoring substance use symptoms of those screened positive during the follow-up visits. We also explore whether patient demographics, clinical presentation, travel distance to community health clinics and provider's experience are related to substance screening and symptom monitoring. Findings from this study may inform efforts to improve the quality of care for patients with substance use problems in primary care settings.

\section{METHODS}

\section{Data Source}

Data was drawn from the Washington State Mental Health Integration Program (MHIP), ${ }^{19}$ a state-wide integrated care program serving safety-net populations at community health clinics across Washington State. The program is based on a collaborative team approach that includes the patient's primary care provider, an on-site care manager and a psychiatric consultant assigned to each clinic-based team. The current study includes adult patients who were recipients of state assistance due to unemployment and temporary disability, and who were determined by their primary care providers as needing treatment for a mental disorder. The majority of participants were enrolled for depression care. A total of 15,843 patients from 133 participating community health clinics enrolled in the program between 2008 and 2011 and completed an initial assessment.

\section{Measures}

Substance Screening and Monitoring. All patients enrolled in the program were tracked in MHIP's web-based patient registry, which incorporated standardized instruments for clinical outcomes tracking. The Global Appraisal of Individual Needs-Short Screener (GAIN-SS) ${ }^{20}$ was used for substance screening, monitoring, and as a measure of symptom severity change. The GAIN-SS is a five-item standardized screener assessing symptoms related to weekly alcohol and drug use, problems caused by use and use-induced withdrawal, with a scoring range from 0 to 5 . A score of $\geq 2$ demonstrates good sensitivity and specificity, and is highly indicative of a positive screen for substance use problems. ${ }^{20,21}$

Rural Urban Classification. The degree of rurality of the clinic's geographical location was classified into small/ isolated rural, large rural, and urban using rural- urban commuting area codes (RUCA). ${ }^{22,23}$ The RUCA classification allows characterization of rural urban areas regarding the city/town size and its functional relationships to the neighboring larger cities and towns. ${ }^{23}$ Clinics' zip codes were mapped onto the RUCA codes and then aggregated into three commonly used categories to approximate its location in relationship with urban areas (RUCA codes: 1.0, 1.1, 2.0, 2.1, 3.0, 4.1, $5.1,7.1,8.1,10.1$ ), large rural towns (RUCA codes: 4.0, 4.2, $5.0,5.2,6.0,6.1$ ) or small/isolated small rural towns (RUCA codes: 7.0, 7.2, 7.3, 7.4, 8.0, 8.2, 8.3, 8.4, 9.0, 9.1, 9.2, 10.0, $10.2,10.3,10.4,10.5,10.6)$. Of 133 participating clinics, 32 clinics are located in small rural, 16 in large rural and 91 in urban areas. Most rural clinics serve larger catchment areas but much smaller populations than urban clinics. In MHIP, the majority of the patients received care from clinics in urban areas $(n=14,344)$, compared to large rural $(n=863)$ and small rural areas $(n=636)$.

Other Variables. The MHIP registry provided patient demographics and clinical data including age, gender, treatment history for mental and substance use problems, suicidal thoughts, Patient Health Questionnaire (PHQ-9) for depression symptom severity, Generalized Anxiety Disorder (GAD-7) for anxiety symptom severity, and psychiatric comorbid conditions of bipolar disorder, post-traumatic stress disorder, psychotic disorder, cognitive disorder and chronic pain. Geocoding was used to calculate travel distance between patient and clinic zip codes, ${ }^{24}$ which was categorized into $<10,10-19$, and $20+$ miles. Patients residing within the clinic zip code were assigned a value of 0.5 mile for analytical purposes. Care managers' experience with the MHIP was categorized as $2+$ or $<2$ years of experience.

\section{Statistical Analysis}

Frequency distributions of substance screening and follow-up monitoring were stratified by rural-urban areas. We used a multilevel Poisson model to assess substance screening and follow-up monitoring with an array of patient-level demographics, clinical presentations, travel distance to care, care manager's experience and clinics' rural urban classifications. As logistic models tend to overestimate risk association when prevalence of the outcome is high, the Poisson model was chosen. $^{25}$ Multilevel modeling accounts for the hierarchical clustering of patients within clinics, with the clinic treated as a random effect with its own intercept. Analysis started with an unconditional model (null model, Model 1) estimating the partition of variability between patient and clinic levels before accounting for any correlate effects; Model 2 added baseline patient-level demographics and clinical presentations; and Model 3 added travel distance, care manager's experience and clinics' rural urban classifications to Model 2 simultaneously. Since evaluation on follow-up monitoring applied to patients who received a substance screening, we conducted a propensity score analysis using a logit model to obtain a 
predicted probability representing the likelihood of receiving a substance screening for each patient. Correlates with a significance level $p<0.10$ were included for propensity score estimation. We repeated the same multilevel modeling with propensity score adjustments ${ }^{26}$ to examine correlates associated with follow-up monitoring. Follow-up monitoring was examined among patients who received a screening and stayed in the program more than 3 months with at least one follow-up treatment contact with their care manager. Analyses were completed in Stata 13. The study was approved by the University of Washington Institutional Review Board.

\section{RESULTS}

The majority of participants were males $(55.9 \%), 30-49$ years of age $(53.2 \%)$, reported thoughts of death and suicide $(55.4 \%)$ and endorsed considerable depression symptoms $(83.6 \%$ of PHQ-9 $\geq 10$ ) and anxiety (78 \% of GAD-7 $\geq 10$ ). Participants in rural and urban clinics differed in demographic and clinical characteristics (Table 1). In particular, more rural residents reported prior treatment for mental and substance use disorders and exhibited greater psychiatric complexities than urban residents.
Patients of small/isolated rural clinics traveled as much as twice the distance of patients of urban clinics to receive care (20.2 vs. 9.7 miles, $p<0.001)$. Compared to care managers in large rural clinics, those care managers in small/isolated rural and urban clinics had a longer period of experience with integrated care.

Approximately three-quarters of participants $(73.6 \%)$ received a substance screening (Table 2). Clinics in large rural areas $(87.8 \%)$ screened more patients than clinics in small/ isolated rural $(79.4 \%)$ and urban settings $(72.5 \%, p<0.001)$. Screening scores were similar across rural and urban areas, although patients treated in urban clinics tended to report slightly higher numbers of substance use symptoms. Of those screened, $14.9 \%$ scored 1 on the screener (13.9\% in small/ isolated rural, $13.9 \%$ in large rural and $15 \%$ in urban), and $25.8 \%$ scored 2 or higher $(23.4 \%$ in small/isolated rural, $20.6 \%$ in large rural and $26.3 \%$ in urban). Figure 1 shows the percentage of follow-up monitoring by initial screening scores and rural urban classifications. Of patients screened positive, $41.4 \%$ received a follow-up monitoring. Overall, rural and urban clinics differed in monitoring patient's substance use symptoms (all rural clinics combined: $28.8 \%$ vs. urban clinics: $42.6 \%, p=0.001)$. Specifically, $13.6 \%$ from small/ isolated rural areas received a follow-up monitoring compared

Table 1. Patient Demographic and Clinical Characteristics by Rural-Urban Classifications of Clinics

\begin{tabular}{|c|c|c|c|c|}
\hline & Total $(n=15843)$ & $\begin{array}{l}\text { Small/Isolated Rural } \\
(n=636)\end{array}$ & Large Rural $(n=863)$ & Urban $(n=14344)$ \\
\hline \multicolumn{5}{|l|}{$\mathrm{Age}^{\mathrm{a}}$} \\
\hline $18-29, n(\%)$ & $3340(21.1)$ & $146(23.2)$ & $209(24.3)$ & $2985(20.8)^{*}$ \\
\hline $30-49, n(\%)$ & $8405(53.2)$ & $323(51.3)$ & $456(53.0)$ & $7626(53.3)$ \\
\hline $50+, n(\%)$ & $4059(25.7)$ & $161(25.5)$ & $195(22.7)$ & $3703(25.9)$ \\
\hline \multicolumn{5}{|l|}{ Gender $^{\mathrm{a}}$} \\
\hline Male, $n(\%)$ & $8759(55.9)$ & $345(54.9)$ & $424(49.5)$ & $7990(56.4)^{*}$ \\
\hline Female, $n(\%)$ & $6907(44.1)$ & $284(45.1)$ & $433(50.5)$ & $6190(43.6)$ \\
\hline Prior treatment for mental disorders, $n(\%)$ & $5987(37.8)$ & $356(56.0)$ & $527(61.1)$ & $5104(35.6)_{*}^{*}$ \\
\hline Prior treatment for substance abuse, $n(\%)$ & $4025(25.4)$ & $178(28.0)$ & $304(35.2)$ & $3543(24.7)_{*}^{*}$ \\
\hline Suicidal thoughts ${ }^{\mathrm{a}}, n(\%)$ & $8132(55.4)$ & $344(55.8)$ & $537(63.6)$ & $7251(54.8)^{*}$ \\
\hline \multicolumn{5}{|l|}{ PHQ-9 $9^{\mathrm{a}}$} \\
\hline$<10, n(\%)$ & $2364(16.4)$ & $111(18.5)$ & $113(13.7)$ & $2140(16.5)^{*}$ \\
\hline $10-19, n(\%)$ & $6580(45.7)$ & $286(47.7)$ & $356(43.1)$ & $5938(45.8)$ \\
\hline $20-27, n(\%)$ & $5445(37.9)$ & $203(33.8)$ & $357(43.2)$ & $4885(37.7)$ \\
\hline Mean (SD) & $16.5(6.6)$ & $15.8(6.6)$ & $17.3(6.3)$ & $16.5(6.6)^{* \prime}$ \\
\hline \multicolumn{5}{|l|}{ GAD- $7^{\mathrm{a}}$} \\
\hline$<10, n(\%)$ & $2739(22.0)$ & $135(23.1)$ & $166(20.7)$ & $2438(22.1)^{*}$ \\
\hline $10-14, n(\%)$ & $2994(24.1)$ & $145(24.9)$ & $162(20.2)$ & $2687(24.3)$ \\
\hline $15-21, n(\%)$ & $6700(53.9)$ & $303(52.0)$ & $474(59.1)$ & $5923(53.6)$ \\
\hline Mean (SD) & $14.1(5.6)$ & $13.6(5.7)$ & $14.7(5.4)$ & $14.1(5.6)^{* \prime}$ \\
\hline \multicolumn{5}{|l|}{ No. of Comorbid conditions ${ }^{b}$} \\
\hline $0, n(\%)$ & $9238(58.9)$ & $351(55.2)$ & $323(37.4)$ & $8654(60.3)^{*}$ \\
\hline $1, n(\%)$ & $4645(29.3)$ & $235(36.9)$ & $378(43.8)$ & $4032(28.1)$ \\
\hline $2+, n(\%)$ & $1870(11.8)$ & $50(7.9)$ & $162(18.8)$ & $1658(11.6)$ \\
\hline \multicolumn{5}{|l|}{ Travel distance $^{\mathrm{a}}$} \\
\hline$<10$ miles, $n(\%)$ & 10712 (68.9) & $324(52.3)$ & $440(51.7)$ & $9948(70.6)$ \\
\hline 10-19 miles, $n(\%)$ & $2551(16.4)$ & $23(3.7)$ & $104(12.2)$ & $2424(17.2)$ \\
\hline $20+$ miles, $n(\%)$ & $2293(14.7)$ & $273(44.0)$ & $307(36.1)$ & $1713(12.2)$ \\
\hline Mean (SD) & $10.4(19.5)$ & $20.2(30.4)$ & $14.9(20.8)$ & $9.7(18.6)^{* \prime}$ \\
\hline \multicolumn{5}{|l|}{ Care manager's experience ${ }^{c}$} \\
\hline$<24$ months, $n(\%)$ & $103(43.1)$ & $12(40.0)$ & $16(64.0)$ & $75(40.8)$ \\
\hline 24 months,$+ n(\%)$ & $136(56.9)$ & $18(60.0)$ & $9(36.0)$ & $109(59.2)$ \\
\hline Mean (SD) & $25.6(16.4)$ & $22.9(8.6)$ & $19.0(11.3)$ & $27.0(16.4)^{*}$ \\
\hline
\end{tabular}

${ }^{*} p<0.05$ for comparisons across rural-urban areas

PHQ-9 Patient Health Questionnaire scale, GAD-7 Generalized Anxiety Disorder scale, S standard deviation

${ }^{a}$ Information was missing for age $(n=39)$, gender $(n=177)$, suicidal thoughts $(n=1160)$, PHQ-9 $(n=1454)$, GAD-7 $(n=3410)$, travel distance $(n=287)$

${ }^{b}$ Comorbid conditions include bipolar disorder, post-traumatic stress disorder, psychotic disorder, cognitive disorder and chronic pains

${ }^{c}$ Based on 239 care managers (30 in small/isolated rural: 25 in large rural, 184 in urban) 
Table 2. Substance Screening Rate and Frequency Distribution of Screening Scores

\begin{tabular}{|c|c|c|c|c|}
\hline & Total & $\begin{array}{l}\text { Small/ } \\
\text { Isolated } \\
\text { Rural }\end{array}$ & $\begin{array}{l}\text { Large } \\
\text { Rural }\end{array}$ & Urban \\
\hline $\begin{array}{l}\text { Substance } \\
\text { screening rate (\%) }\end{array}$ & 73.6 & 79.4 & 87.8 & $72.5^{*}$ \\
\hline \multicolumn{5}{|c|}{ Screening Score ${ }^{\mathrm{a}}(\%)$} \\
\hline 0 & 59.3 & 62.8 & 65.5 & $58.7^{*}$ \\
\hline 1 & 14.9 & 13.9 & 13.9 & 15.0 \\
\hline 2 & 6.1 & 6.9 & 4.9 & 6.2 \\
\hline 3 & 4.1 & 3.5 & 2.6 & 4.3 \\
\hline 4 & 5.0 & 4.0 & 3.6 & 5.1 \\
\hline 5 & 10.6 & 8.9 & 9.5 & 10.7 \\
\hline Mean (SD) & $1.1(1.7)$ & $1.0(1.6)$ & $0.9(1.6)$ & $1.1(1.7)^{*}$ \\
\hline
\end{tabular}

with $40.0 \%$ from large rural and $42.6 \%$ from urban clinics $(p<0.001)$. Among patients who scored zero on the initial screening, more patients in large rural (36.6\%) and urban (36\%) clinics received a reassessment than did those in small/isolated rural clinics $(7.5 \%, p<0.001)$.

Differences across clinics are explained in part by patient, care manager and rural-urban classification variables (Table 3). There were significant variations between clinics in screening substance use [clinic-level variance $=0.111$, Standard error $(\mathrm{SE})=0.019$, Model 1] and monitoring substance use problems at follow-up visits [clinic-level variance: 1.130, $\mathrm{SE}=0.215$, Model 1]. With regard to substance screening, individual-level variables remained significant after adding travel distance, care manager's experience and rural- urban classifications to the model (Model 3). The results demonstrated that prior treatment for mental or substance use disorder, PHQ-9 score, comorbid conditions and care manager's experience were significantly associated with an increased likelihood of substance screening. Adding patient demographics and clinical presentations into the model reduced variance from 0.111 to 0.038 , a $65.8 \%$ reduction from the null model.

With regard to follow-up monitoring, patient demographics and clinical presentations explained little $(0.9 \%)$ of the cliniclevel variance (Model 2). Controlling for patient-level variables, travel distance, care manager's experience and rural urban classifications (Model 3) explained another $8.6 \%$ of the variance. Model 3, where all variables were added simultaneously with propensity score adjustments, showed that initial screening score and care manager's experience were positively associated with substance monitoring, but travel distance was negatively associated with substance monitoring. Notably, patients of urban clinics were 2.3 times more likely to receive follow-up monitoring for their substance use problem than patients of small/isolated rural clinics $(p=0.02)$. In a supplement analysis without propensity score adjustments, the association of rural urban areas remained strong and significant above and beyond all other variables (relative risk: 2.3, $p=0.02$ ). Interactions of rural urban areas with each correlate were explored and no significant interaction was found. Across models, clinic-level variances were all significant, indicating strong clustering effects among patients of the same clinic.

\section{DISCUSSION}

Across both rural and urban settings, approximately threequarters of primary care-based patients were screened for substance use while receiving care for their mental health problems. Although the majority of community health clinics complied with the state's guideline in screening patients for

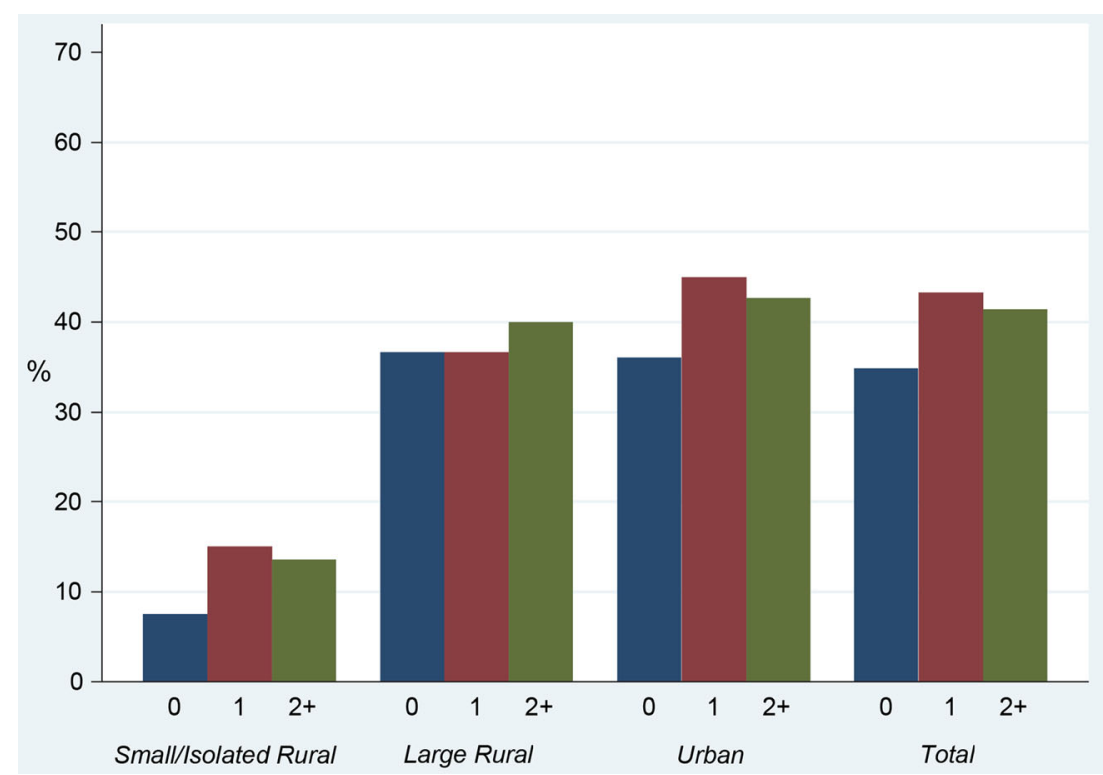

Figure 1. Percentage of follow-up monitoring by initial screening scores and rural-urban classifications. 
Table 3. Correlates Associated with Substance Screening and Monitoring

\begin{tabular}{|c|c|c|c|c|c|c|c|c|c|c|c|c|}
\hline & \multicolumn{6}{|c|}{ Substance screening } & \multicolumn{6}{|c|}{ Substance monitoring $^{\mathbf{b}}$} \\
\hline & \multicolumn{2}{|c|}{ Model 1} & \multicolumn{2}{|c|}{ Model 2} & \multicolumn{2}{|c|}{ Model 3} & \multicolumn{2}{|c|}{ Model 1} & \multicolumn{2}{|c|}{ Model 2} & \multicolumn{2}{|c|}{ Model 3} \\
\hline & $\mathbf{R R}$ & $\begin{array}{l}95 \% \\
\text { CI }\end{array}$ & $\mathbf{R R}$ & $95 \% \mathrm{CI}$ & $\mathbf{R R}$ & $95 \%$ CI & $\mathbf{R R}$ & $\begin{array}{l}95 \% \\
\text { CI }\end{array}$ & $\mathbf{R R}$ & $95 \%$ CI & $\mathbf{R R}$ & $95 \%$ CI \\
\hline \multicolumn{13}{|l|}{ Age } \\
\hline $18-29$ & & & 1 & & 1 & & & & 1 & & 1 & \\
\hline $30-49$ & & & 0.99 & $0.95,1.04$ & 0.99 & $0.95,1.04$ & & & 1.00 & $0.90,1.11$ & 1.00 & $0.90,1.11$ \\
\hline $50+$ & & & 0.97 & $0.92,1.03$ & 0.98 & $0.92,1.03$ & & & 1.04 & $0.93,1.17$ & 1.05 & $0.93,1.18$ \\
\hline Male & & & 1.02 & $0.98,1.06$ & 1.02 & $0.98,1.06$ & & & 1.00 & $0.92,1.08$ & 0.99 & $0.92,1.08$ \\
\hline $\begin{array}{l}\text { Prior treatment for mental } \\
\text { disorder }\end{array}$ & & & 1.06 & $1.02,1.11^{*}$ & 1.07 & $1.02,1.11^{*}$ & & & 0.98 & $0.89,1.09$ & 1.00 & $0.90,1.11$ \\
\hline $\begin{array}{l}\text { Prior treatment for } \\
\text { substance abuse }\end{array}$ & & & 1.06 & $1.02,1.10^{*}$ & 1.06 & $1.02,1.11^{*}$ & & & 1.07 & $0.96,1.19$ & 1.09 & $0.97,1.21$ \\
\hline Suicidal thoughts & & & 1.01 & $0.97,1.05$ & 1.01 & $0.97,1.05$ & & & 0.98 & $0.90,1.07$ & 0.98 & $0.90,1.07$ \\
\hline \multicolumn{13}{|l|}{ PHQ-9 score } \\
\hline 0-9 & & & 1 & & 1 & & & & 1 & & 1 & \\
\hline $10-19$ & & & 1.07 & $1.00,1.14^{*}$ & 1.07 & $1.00,1.14^{*}$ & & & 0.97 & $0.86,1.10$ & 0.98 & $0.86,1.11$ \\
\hline $20-27$ & & & 1.09 & $1.02,1.18^{*}$ & 1.09 & $1.02,1.17^{*}$ & & & 1.00 & $0.86,1.16$ & 1.01 & $0.87,1.18$ \\
\hline \multicolumn{13}{|l|}{ GAD-7 score } \\
\hline $0-9$ & & & 1 & & 1 & & & & 1 & & 1 & \\
\hline $10-14$ & & & 0.96 & $0.90,1.02$ & 0.96 & $0.90,1.02$ & & & 1.02 & $0.90,1.15$ & 1.01 & $0.90,1.14$ \\
\hline $15-21$ & & & 0.94 & $0.89,1.00^{*}$ & 0.94 & $0.89,1.00$ & & & 0.99 & $0.88,1.11$ & 0.99 & $0.87,1.11$ \\
\hline \multicolumn{13}{|l|}{ No. comorbid disorder ${ }^{a}$} \\
\hline 0 & & & 1 & & 1 & & & & 1 & & 1 & \\
\hline 1 & & & 1.07 & $1.03,1.12^{*}$ & 1.08 & $1.03,1.12^{*}$ & & & 1.04 & $0.94,1.15$ & 1.06 & $0.96,1.18$ \\
\hline $2+$ & & & 1.10 & $1.03,1.16^{*}$ & 1.10 & $1.04,1.17^{*}$ & & & 0.94 & $0.81,1.10$ & 0.98 & $0.84,1.15$ \\
\hline \multicolumn{13}{|l|}{ Substance screening score } \\
\hline 0 & & & & & & & & & 1 & & 1 & \\
\hline 1 & & & & & & & & & 1.14 & $1.02,1.26^{*}$ & 1.13 & $1.02,1.26^{*}$ \\
\hline $2+$ & & & & & & & & & 1.20 & $1.09,1.32^{*}$ & 1.20 & $1.09,1.32^{*}$ \\
\hline \multicolumn{13}{|l|}{ Travel distance (miles) } \\
\hline$<10$ & & & & & 1 & & & & & & 1 & \\
\hline $10-19$ & & & & & 1.01 & $0.96,1.06$ & & & & & 1.01 & $0.91,1.12$ \\
\hline $20+$ & & & & & 1.00 & $0.94,1.06$ & & & & & 0.88 & $0.77,0.99^{*}$ \\
\hline $\begin{array}{l}\text { CM's experience } 24 \text { months } \\
+ \text { (vs less than } 24 \text { months) }\end{array}$ & & & & & 1.09 & $1.02,1.16^{*}$ & & & & & 1.22 & $1.03,1.45^{*}$ \\
\hline Rural-urban classification & & & & & 1 & & & & & & 1 & \\
\hline Small/Isolated rural & & & & & & & & & & & & \\
\hline Large rural & & & & & 1.09 & $0.89,1.33$ & & & & & 1.07 & $0.38,3.01$ \\
\hline Urban & & & & & 1.07 & $0.92,1.24$ & & & & & 2.29 & $1.13,4.63^{*}$ \\
\hline \multicolumn{13}{|l|}{ Random effects } \\
\hline Variance (SE) & $\begin{array}{l}0.111 \\
(0.01\end{array}$ & & 0.03 & $(0.008)$ & 0.037 & $(0.008)$ & $\begin{array}{l}1.13 \\
(0.21\end{array}$ & & 1.120 & $(0.214)$ & 1.033 & $(0.199)$ \\
\hline
\end{tabular}

RR relative risk, $95 \%$ CI $95 \%$ confidence interval, SE standard error, PHQ-9 Patient Health Questionnaire scale, GAD-7 Generalized Anxiety Disorder scale, CM care manager

${ }^{a}$ Number of comorbid conditions includes bipolar disorder, post stress traumatic stress disorder, psychotic disorder, cognitive disorder and chronic pains

${ }^{b}$ Mixed effects models for substance monitoring were adjusted for propensity scores. Propensity score of substance screening receipt was calculated using a logit model with correlates of treatment history of mental health, treatment history of substance abuse, PHQ-9 score, comorbid conditions and care manager's experience. Missing values were included as separate categories ${ }^{*} p<0.05$

substance use, few clinics provided timely symptom followups for those screening positive. Patients in small/isolated rural clinics were least likely to be monitored for substance use during follow-up care. These findings underscore that while many rural communities lack access to specialty care, rural-urban differences tend to be exacerbated in small, remote rural areas that are likely affected most by the shortages of behavioral health professionals and facilities.

Despite guidelines from the US Preventive Services Task Force recommending alcohol screening to identify patients who may benefit from brief intervention ${ }^{27}$ and the passage of reimbursement for screening and brief intervention by Medicare, most health care organizations have not implemented alcohol or drug use screening in routine care. ${ }^{28}$ In this program, state guidelines suggest routine screening of all new patients in the program, and screening rates are close to those reported from Veterans Administration primary care settings ${ }^{29}$. More than a quarter of patients, however, were not screened. Additionally, one quarter of the patients scored $\geq 2$ on the screener and $10 \%$ of the patients endorsed all five substance use symptoms, indicating the rates of substance use problems in this population are substantial. The proportion of positive screenings appears to be uniform across rural and urban areas, suggesting that regardless of geographical location, comorbid mental and substance abuse conditions are common in this safety-net population seeking care from community health clinics. In order to provide timely intervention before substance use problems become debilitating, it is suggested that substance screening and monitoring be integrated as part of routine primary care. 
Our analyses show that patients who had prior treatment for mental or substance use disorder and who exhibited greater psychopathology were more likely to receive a screening. These findings are in line with the notion that targeted efforts should be aimed at high-risk populations to improve the overall effectiveness of screening and case finding. While screening is the first step in identifying at-risk individuals, the effectiveness of screening is valuable only when ongoing symptom monitoring and intervention are available for those identified as at risk. This study thus further examined whether community health clinics provided follow-up monitoring for patients who screened positive for a substance use problem. We found that only two-fifths were actually followed up while receiving treatment for their mental disorder. The biggest disparities were found in patients of small, isolated rural clinics and those who traveled longer distances to receive care. Earlier research has highlighted that lack of recognizing substance use as a problem in small rural towns explains much of the low rate of treatment utilization in rural areas. ${ }^{30}$ For patients treated for mental disorders, inadequate follow-up monitoring for co-occurring substance use problems likely results in missed opportunities to intervene and impact the effectiveness of mental and other health care provided.

Most preventive and disease management services are provided in primary care, and primary care providers rely on routine screening and monitoring to identify problems, promote wellness and initiate treatment. Due to the shortage of specialists, rural residents are more likely than their urban counterparts to rely on primary care providers for mental health and substance abuse services. ${ }^{16,31,32}$ This is particularly true for low-income, uninsured rural residents. Research has shown that limited resources, competing demands, and lack of time and training may impede primary care clinics and providers in managing patients with substance use problems. ${ }^{33-36}$ These barriers could be more prominent in community health clinics. The limited study data prohibited further examinations of these barriers; however, our finding of a positive association between care manager's experience and providing substance screening and monitoring highlights the importance of training and experience of health care providers in managing patients with substance use disorders.

The observed low rate of follow-up for substance use in both rural and urban clinics may reflect the limited capacity of the current integrated mental health program in managing patients with co-occurring mental and substance use disorders. Emerging evidence has suggested that brief interventions, especially repeated brief interventions, are effective in reducing patients' hazardous drinking ${ }^{37-43}$, enhancing problematic drug use reduction ${ }^{44}$ and increasing treatment entry and attendance. ${ }^{45}$ Brief intervention, on the other hand, has also shown secondary benefits in improving patients' mental health functioning. ${ }^{46}$ A recent study further demonstrated that alcohol care management could be effectively delivered in primary care settings, leading to better treatment access and health improvement. ${ }^{47}$ To implement such changes in primary care, process improvement models such as Network for the Improvement of Addiction Treatment ${ }^{48}$ may help accommodate unique resources and needs in these rural settings. Training on brief intervention skills and focusing clinic process improvements on co-occurring disorders are thus important next steps.

Additional strategies, such as telehealth or adding an addiction consulting specialist to the integrated care team, may be useful in bridging treatment access barriers and facilitating the integration of substance abuse treatment into primary care practices. Incorporating substance abuse diagnosis and treatment into medical training and increasing online and telehealth based educational resources will help prepare physicians with needed knowledge and skills to care for patients with substance use disorders. ${ }^{49,50}$ Adoption of information and communication technologies ${ }^{51-53}$ such as technology-assisted interventions and mobile devices may further enhance the continuum of care and facilitate access to consultation from addiction specialists who are often not available in rural settings.

Using data from a state-wide integrated care program allows us to systematically evaluate substance screening and monitoring patterns, especially in largely understudied rural, geographic areas. The screening rate is slightly higher than in a previous report ${ }^{54}$ where substance screening was evaluated using earlier cohorts of intake assessment data from MHIP. In this study, we reviewed intake and follow-up data to identify whether a patient was ever screened for substance use and whether follow-up monitoring was made for those identified as at-risk at the initial screening. While our analysis revealed discernible differences in patient, care manager and rural urban characteristics with regard to substance screening and monitoring, our variance component analysis from multilevel modeling suggests there may be other important contextual factors to consider for future research (e.g., previously mentioned primary care system and provider barriers). Additionally, lack of transportation, service costs, and perceived stigma associated with substance abuse treatments may prevent rural residents from seeking and participating in treatment, which may result in refusal to complete screening and follow-up assessments. ${ }^{55,56}$

Notwithstanding, our findings show that substance use problems are prevalent among primary care patients enrolled in this mental health integration program. While initial substance screening was associated with patient's treatment history and severity of psychopathology, follow-up monitoring was appreciably associated with clinics' rural- urban geographical locations. Timely follow-up on patient's substance use remained overlooked in both rural and urban areas, with the biggest disparities found to be in small, remote rural areas. Clinics in large rural towns tend to provide timely follow-up more often than clinics in small/isolated rural towns. One of the explanations could be that clinics in large rural towns have better access to adjacent metropolitan areas for substance treatment services, while clinics in small/isolated rural towns largely suffer from lack of access and resources. The low rate of symptom monitoring is a key challenge in reducing health 
disparities between rural and urban areas in caring for patients with substance use problems. Study findings further demonstrate that using a more refined geographic typology may be needed in distinguishing residents of the most remote/isolated areas from residents of other rural areas with regard to access to care. Our findings reinforce prior research that health care disparities correspond to the degree of rurality, with residents in more remote areas facing the greatest challenges in access to care as compared to rural areas that are closer to urban centers. Future research could focus on developing collaborative care models that incorporate brief interventions, telehealth and mobile health technologies to improve engagement and service delivery for patients with substance use disorders in remote rural settings.

Acknowledgements: This research project was supported by the Life Sciences Development Fund (LSDF), Washington State University, Rural Mental Health and Substance Abuse Treatment, Program of Excellence Seed Grant (109212-G003109). The authors would like to thank the Community Health Plan of Washington (CHPW) and Public Health of Seattle and King County (PHSKC) for sponsorship and funding of the Mental Health Integration Program (MHIP) and for data on the quality of care and outcomes.

Conflict of Interest: The authors declare that they do not have a conflict of interest. CHPW and PHSKC provided funding for the collection of the data used in the analyses presented in the context of MHIP, an ongoing statewide quality improvement effort that integrates mental health care into community health clinics. Authors affiliated with the University of Washington were supported through a contract from CHPW and PHSKC to provide training and technical assistance related to the MHIP described (YF Chan, J Unützer), and a T-32 Geriatric Mental Health Fellowship (MHO73553, T Hoeft).

Corresponding Author: Ya-Fen Chan, PhD; Department of Psychiatry Behavioral Sciences, School of Medicine, University of Washington, Seattle, WA, USA (e-mail: ufcuw@uw.edu).

\section{REFERENCES}

1. SAMHSA. Results from the 2013 National Survey on Drug Use and Health: Summary of National Findings. NSDUH Series H-48, HHS Publication No. (SMA) 14-4863. Rockville: SAMHSA; 2014.

2. Momper SL, Delva J, Tauiliili D, Mueller-Williams AC, Goral P. OxyContin use on a rural midwest American Indian reservation: demographic correlates and reasons for using. Am J Public Health 2013;103(11): 1997-9.

3. Patrick ME, Schulenberg JE, Martz ME, Maggs JL, O'Malley PM, Johnston L. Extreme binge drinking among 12th-grade students in the U.S.: prevalence and predictors. JAMA Pediatr. 2013;167(11):1019-2015.

4. Quality SCfBHSa. TEDS Report: A Comparison of Rural and Urban Substance Abuse Treatment Admissions Rockville, MD.2012.

5. Harris KM, Edlund MJ. Use of mental health care and substance abuse treatment among adults with co-occurring disorders. Psychiatr Serv. 2005;56(8):954-9.

6. Cohen E, Feinn R, Arias A, Kranzler HR. Alcohol treatment utilization: findings from the National Epidemiologic Survey on Alcohol and Related Conditions. Drug Alcohol Depend. 2007;86(2-3):214-21.

7. Mojtabai R. Use of specialty substance abuse and mental health services in adults with substance use disorders in the community. Drug Alcohol Depend. 2005;78:345-54.

8. Oser CB, Leukefeld CG, Tindall MS, et al. Rural drug users: factors associated with substance abuse treatment utilization. Int $\mathrm{J}$ Offender Ther Comp Criminol. 2011;55(4):567-86.
9. Casey MM, Thiede Call K, Klingner JM. Are rural residents less likely to obtain recommended preventive healthcare services? Am J Prev Med. 2001;21(3): 182-8.

10. Larson S, Correa-de-Araujo R. Preventive health examinations: a comparison along the rural-urban continuum. Womens Health Issues. 2006; 16(2):80-8.

11. Agency for Healthcare Research and Quality. Rockville, MD 2012 National Healthcare Disparities Report. http://archive.ahrq.gov/research/findings/ nhqrdr/nhdr12/index.html Accessed June 26, 2015.

12. Hauenstein EJ, Petterson S, Rovnyak V, Merwin E, Heise B, Wagner D. Rurality and mental health treatment. Adm Policy Ment Health. 2007;34(3):255-67.

13. Adams SJ, Xu S, Dong F, Fortney J, Rost K. Differential effectiveness of depression disease management for rural and urban prumary care patients. J Rural Health. 2006;22(4):343-50.

14. Wu LT, Kouzis AC, Schlenger WE. Substance use, dependence, and service utilization among the US uninsured nonelderly population. Am J Public Health. 2003;93(12):2079-85.

15. Schmidt LA, Ye Y, Greenfield TK, Bond J. Ethnic disparities in clinical severity and services for alcohol problems: results from the National Alcohol Survey. Alcohol Clin Exp Res. 2007;31(1):48-56.

16. Wang $\mathbf{P}$, Lane $\mathbf{M}$, Olfson $\mathbf{M}$, Pincus $\mathbf{H}$, Wells $\mathbf{K}$, Kessler $\mathbf{R}$. Twelve-month use of mental health services in the United States: results from the National Comorbidity Survey Replication. Arch Gen Psychiatry. 2005;62(6):629-40.

17. Druss B, Bornemann T, Fry-Johnson Y, McCombs H, Politzer R, Rust G. Trends in mental health and substance abuse services at the nation's community health centers: 1998-2003. Am J Public Health. 2008;98(9 Suppl):S126-31.

18. Wells R, Morrissey JP, Lee IH, Radford A. Trends in behavioral health care service provision by community health centers, 1998-2007. Psychiatr Serv. 2010;61(8):759-64.

19. Mental Health Integration Program. http://integratedcare-nw.org/ Accessed at June 25, 2015.

20. Dennis M, Chan Y-F, Funk R. Development and validation of the GAIN Short Screener (GSS) for internalizing, externalizing and substance use disorders and crime/violence problems among adolescents and adults. Am J Addict. 2006; 15(Suppl 1):80-91.

21. McDonell MG, Comtois KA, Voss WD, Morgan AH, Ries RK. Global Appraisal of Individual Needs Short Screener (GSS): Psychometric Properties and Performance as a Screening Measure in Adolescents. Am J Drug Alcohol Abuse. 2009;35(3): 157-60.

22. Rural Health Research Center. University of Washington. Seattle, Washington. http://depts.washington.edu/uwruca/ Accessed at June 25, 2015.

23. Berke EM, West AN, Wallace AE, Weeks WB. Practical and policy implications of using different rural-urban classification systems: a case study of inpatient service utilization among Veterans Administration users. J Rural Health. 2009;25(3):259-66.

24. Ozimek A, Miles D. Stata utilities for geocoding and generating travel time and travel distance information. Stata J. 2011;11(1):106-19.

25. Zou G. A modified poisson regression approach to prospective studies with binary data. Am J Epidemiol. 2004;159(7):702-6.

26. Rubin D. Estimating causal effects from large data sets using propensity scores. Ann Int Med. 1997; 127(8S):757-63.

27. Jonas DE, Garbutt JC, Amick HR, et al. Behavioral counseling after screening for alcohol misuse in primary care: a systematic review and meta-analysis for the U.S. Preventive Services Task Force. Ann Intern Med. 2012;157(9):645-54.

28. Williams EC, Johnson ML, Lapham GT, et al. Strategies to implement alcohol screening and brief intervention in primary care settings: a structured literature review. Psychol Addict Behav. 2011;25(2):206-14.

29. Desai MM, Rosenheck RA, Craig TJ. Screening for alcohol use disorders among medical outpatients: the influence of individual and facility characteristics. Am J Psychiatry. 2005;162(8):1521-6.

30. Warner BD, Leukefeld CG. Rural-urban differences in substance use and treatment utilization among prisoners. Am J Drug Alcohol Abuse. 2001;27(2):265-80.

31. Lambert D, Agger M, Hartley D. Service use of rural and urban Medicaid beneficiaries suffering from depression: the role of supply. J Rural Health. 1999; 15(3):344-55.

32. Rosenblatt RA, Andrilla CH, Catlin M, Larson EH. Geographic and Specialty Distribution of US Physicians Trained to Treat Opioid Use Disorder. Ann Fam Med. 2015;13(1):23-6.

33. Barry KL, Blow FC, Willenbring ML, McCormick R, Brockmann LM, Visnic S. Use of Alcohol Screening and Brief Interventions in Primary Care Settings:Implementation and Barriers. Subst Abus. 2004;25(1):27-36. 
34. Friedmann PD, McCullough D, Chin MH, Saitz R. Screening and intervention for alcohol problems. A national survey of primary care physicians and psychiatrists. J Gen Intern Med. 2000;15(2):84-91.

35. Miller NS, Sheppard LM, Colenda CC, Magen J. Why physicians are unprepared to treat patients who have alcohol- and drug-related disorders. Acad Med. 2001;76(5):410-8.

36. Brems C, Johnson ME, Warner TD, Roberts LW. Barriers to healthcare as reported by rural and urban interprofessional providers. J Interprof Care. 2006;20(2):105-18.

37. Fleming MF, Manwell LB, Barry KL, Adams w. Stauffacher EA. Brief physician advice for alcohol problems in older adults: a randomized community-based trial. J Fam Pract. 1999;48(5):378-84.

38. Willenbring $\mathbf{M L}$, Olson DH. A randomized trial of integrated outpatient treatment for medically ill alcoholic men. Arch Intern Med. 1999;159(16): 1946-52.

39. Kaner EF, Beyer F, Dickinson HO, et al. Effectiveness of brief alcohol interventions in primary care populations. Cochrane Database Syst Rev. 2007(2):CD004148.

40. Brown RL, Saunders LA, Bobula JA, Mundt MP, Koch PE. Randomizedcontrolled trial of a telephone and mail intervention for alcohol use disorders: three-month drinking outcomes. Alcohol Clin Exp Res. 2007;31(8):1372-9.

41. Helzer JE, Rose GL, Badger GJ, et al. Using interactive voice response to enhance brief alcohol intervention in primary care settings. J Stud Alcohol Drugs. 2008;69(2):251-8.

42. Solberg LI, Maciosek MV, Edwards NM. Primary care intervention to reduce alcohol misuse ranking its health impact and cost effectiveness. Am J Prev Med. 2008;34(2): 143-52.

43. Baker AL, Kavanagh DJ, Kay-Lambkin FJ, et al. Randomized controlled trial of cognitive-behavioural therapy for coexisting depression and alcohol problems: short-term outcome. Addiction. 2010;105(1):87-99.

44. Madras BK, Compton WM, Avula D, Stegbauer T, Stein JB, Clark HW. Screening, brief interventions, referral to treatment (SBIRT) for illicit drug and alcohol use at multiple healthcare sites: comparison at intake and 6 months later. Drug Alcohol Depend. 2009;99(1-3):280-95.

45. Krupski A, Sears JM, Joesch JM, et al. Impact of brief interventions and brief treatment on admissions to chemical dependency treatment. Drug Alcohol Depend. 2010;110(1-2):126-36.
46. Cucciare MA, Boden MT, Weingardt KR. Brief alcohol counseling improves mental health functioning in Veterans with alcohol misuse: results from a randomized trial. J Affect Disord. 2013;147(1-3):3127.

47. Oslin DW, Lynch KG, Maisto SA, et al. A randomized clinical trial of alcohol care management delivered in Department of Veterans Affairs primary care clinics versus specialty addiction treatment. J Gen Intern Med. 2014;29(1):162-8.

48. Gustafson DH, Guanbeck AR, Robinson JM, et al. Which elements of improvement collaboratives are most effective? A cluster-randomized trial. Addiction. 2013;108(6):1145-57.

49. Renner JA Jr, Quinones J, Wilson A. Training psychiatrists to diagnose and treat substance abuse disorders. Curr Psychiatry Rep. 2005;7(5):3529.

50. Polydorou S, Gunderson EW, Levin FR. Training physicians to treat substance use disorders. Curr Psychiatry Rep. 2008;10(5):399404

51. Marsch LA, Dallery J. Advances in the psychosocial treatment of addiction: the role of technology in the delivery of evidence-based psychosocial treatment. Psychiatr Clin North Am. 2012;35(2):481-93.

52. Gustafson DH, Shaw BR, Isham A, Baker T, Boyle MG, Levy M. Explicating an evidence-based, theoretically informed, mobile technologybased system to improve outcomes for people in recovery for alcohol dependence. Subst Use Misuse. 2011;46(1):96-111.

53. Marsch LA, Guarino H, Acosta M, et al. Web-based behavioral treatment for substance use disorders as a partial replacement of standard methadone maintenance treatment. J Subst Abuse Treat. 2014;46(1):4351.

54. Chan Y-F, Huang H, Sieu N, Unützer J. Substance screening and treatment referral in an integrated mental health care program. Psychiatr Serv. In press: 2012

55. Fortney J, Mukherjee S, Curran G, Fortney S, Han X, Booth BM. Factors associated with perceived stigma for alcohol use and treatment among at-risk drinkers. J Behav Health Serv Res. 2004;31(4):418-29.

56. Sexton RL, Carlson RG, Leukefeld CG, Booth BM. Barriers to formal drug abuse treatment in the rural south: a preliminary ethnographic assessment. J Psychoactive Drugs. 2008;40(2):121-9. 